\title{
Pengaruh Penggunaan Gadget terhadap Akhlak Remaja
}

\author{
Nur Hapipa Siregar ${ }^{1}$, Rahmi Wiza ${ }^{2}$ \\ Jurusan Ilmu Agama Islam, Fakultas Ilmu Sosial, Universitas Negeri Padang, Indonesia ${ }^{1 \text {, }}$ \\ nurhapipahsiregar18@gmail.com ${ }^{1}$, rahmiwiza@ fis.unp.ac.id ${ }^{2}$
}

\begin{abstract}
The background of this research is the lack of good morals of teenagers in Simanuldang Jae Village which is caused by excessive use of gadgets. The purpose of this study is to find out how much influence the use of gadgets on adolescent morals and how the positive and negative effects of using gadgets on adolescent morals in Simanuldang Jae Village, Ulu Barumun District, Padang Lawas Regency. This type of research is quantitative by using the correlation method. The sample in this study were 42 people. To test the hypothesis the researcher used simple linear regression data analysis. Based on the results of the study, the coefficient of determination is $\left(R^{2}\right)$ of 0.19 , meaning that there is an effect of the use of gadgets $\backslash$ on the morals of adolescents in Simanuldang jae village by 19\%. And the positive effect of using gadgets on the morals of adolescents in Simanuldang Jae Village is that they watch Islamic-based videos so that it has a good effect on their morals. While the negative effect is that adolescents are less obedient to their parents' orders due to excessive use of gadgets.
\end{abstract}

Keywords: Gadgets, Morals, Teenagers

\section{Pendahuluan}

Gadget adalah sebuah elektronik yang memiliki fungsi sebagai alat komunikasi dan sumber informasi, Contohnya yaitu smartphone, laptop dan komputer khusus (Ishomuddin, 2014: 340). Gadget mempunyai dampak negatif dan positif terutama dikalangan remaja. Menurut Hasibi dkk (2020: 49) dampak positif penggunan gadget yaitu dapat meningkatkan ekonomi seperti bisnis online, mempermudah manusia untuk berkomunikasi, mengakses berbagai macam informasi, meningkatkan wawasan dan pengetahuan serta sebagai hiburan. Sedangkan dampak negatif dari penggunaan gadget menurut Iqbal (2018: 106-107) yaitu manusia lebih banyak berinteraksi dimedia sosial seperti di whatsaap, instagram, facebook dan game daripada dengan lingkungan sekitarnya. Gadget dapat menyebabkan kecanduan yang mengakibatkan banyaknya remaja yang melalaikan tugas sekolah bahkan sampai putus sekolah serta gadget dapat menimbulkan tindak kriminal bagi remaja.

Remaja merupakan anak-anak yang sudah diterapkan padanya beban hukum sebagaiamana orang dewasa (Rochmah, 2017: 193). Remaja juga merupakan masa pancaroba dari kanak-kanak ke masa dewasa yang ditandai dengan adanya perubahan psikologis, biologis dan perubahan sosial pada anak. Remaja juga ditandai dengan sifat susah diatur dan mulai menginginkan kebebasan dalam mengemukakan pendapat. Batas umur remaja bagi perempuan dimulai dari umur 21 tahun sampai dengan umur 21 tahun. Sedangkan batas umur remaja bagi laki-laki yaitu mulai dari umur 13 tahun sampai umur 22 tahun (Novrian, 2017: 35). Menurut Putro (2017: 26) remaja 
mempunyai 4 ciri-ciri yaitu (1) remaja mulai menginginkan kebebasan dalam mengemukakan pendapat, (2) mudah terpengaruh oleh lingkungan dan teman sebaya. (3) Pertumbuhan fisik dan mental yang luar biasa. (4) Emosionalnya semakin meningkat dan sulit menerima nasehat dan arahan dari orang lain.

Akhlak memiliki peran penting dalam kehidupan manusia. Akhlak berasal dari bahasa arab yaitu khuluqun yang artinya perangai atau kebiasaan. Sedangkan menurut istilah akhlak adalah baik dan buruknya kebiasaan seseorang yang mengatur pergaulannya dan menentukan tujuan serta arah kebiasaannya (Habibah, 2015: 73).

Hasil awal observasi peneliti pada bulan Agustus tahun 2020 yang bertempat di Desa Simanuldang Jae Kecamatan Ulu Barumun Kabupaten Padang Lawas yaitu penggunaan gadget terhadap remaja cenderung berdampak negatif. Seringkali remaja di Desa Simanuldang Jae menghabiskan waktunya dengan bermain gadget, sehingga menyebabkan mereka kurang patuh terhadap perintah orangtua dan perintah agama. Mereka tidak jarang menonton film atau video yang belum pantas ditonton seusia remaja sehingga berpengaruh buruk terhadap akhlaknya. Oleh karena itu peneliti tertarik mengkaji dan membahas lebih dalam tentang pengaruh penggunaan gadget terhadap akhlak remaja di Desa Simanuldang Jae Kecamatan Ulu Barumun Kabupaten Padang Lawas. Penelitian ini Bertujuan untuk mengetahui seberapa besar pengaruh penggunaan gadget terhadap akhlak remaja serta bagaimana pengaruh positif dan negatif penggunaan gadget terhadap akhlak remaja di Desa Simanuldang Jae Kecamatan Ulu Barumun Kabupaten Padang Lawas.

Perbedaan penelitian ini dengan penelitian sebelumnya yaitu pada penelitian Riska Ardia Nova (2019) yang berjudul "dampak penggunaan smartphone terhadap akhlak remaja di Desa Latitik Kecamatan Simeulue" yaitu terdapat pada lokasi penelitian.

\section{Tinjauan Pustaka}

Gadget adalah sebuah alat elektronik yang terus mengalami pembaharuan yang bertujuan untuk memudahkan manusia dalamj berkomunikasi dan mengakses berbagai macam informasi. Komunikasi adalah proses pertukaran ide dan penyampaian pesan oleh seseorang atau sekelompok orang kepada orang lain yang bertujuan agar saling terhubung dengan lingkungan sekitar (Nofrion, 2016: 1). Sedangkan informasi yaitu suatu data atau bahan yang telah disiapkan yang sifatnya berguna dan berarti bagi penerima (Andalia \& Seiawan, 2015).

Rosyadi (2019: 97) menyatakan bahwa gadget berkembang dari masa kemasa dimulai dari pesawat elekronik telepon sampai kepada handphone (HP). Perbedaan antara pesawat elektronik telepon dengan handphone yaitu pesawat elektronik telepon masih menggunakan kabel untuk berkomunikasi. Sedangkan handphone bersifat portabel tanpa menggunakan kabel. HP pertama kali digunakan dinegara Amerika Serikat pada tahun 1974 dan akhirnya menyebar keseluruh dunia.

Manfaat penggunaan gadget menurut Syahyuddin (2019: 276) di antaranya yaitu sebagai alat komunikasi. Zaman dahulu manusia berkomunikasi masih manual yaitu dengan menggunakan surat menyurat. Tetapi sekarang ini manusia berkomunikasi dengan siapapun dan dimanapun sangatlah mudah yaitu dengan menggunakan Gadget seperti handphone, laptop dan sebagainya. Manfaat yang kedua yaitu interaksi sosial, 
dengan berbagai fitur aplikasi yang ada di dalam gadget sehingga interaksi sosial yang pada awalnya harus bertatap muka sekarang tidak harus bertatap muka. Gadget juga dapat mempererat tali silaturrahmi, memperbanyak teman serta dapat berhubungan dengan jutaan orang dibelahan dunia. Pendidikan juga manfat dari gadget dimana tidak hanya terfokus pada papan tulis dan spidol saja, dengan mengakses berbagai macam aplikasi yang ada di dalam gadget dapat memudahkan dan melancarkan proses manusia dalam menempuh pendidikan. Manfaat selanjutnya yaitu sarana hiburan yang memuat berbagai fitur aplikasi yang ada di dalam gadget seperti video, musik, game, dan juga perangkat lunak lainnya dapat dijadikan sebagai sarana hiburan. Manfaat terakhir yaitu untuk mengakses informasi dan menambah wawasan. Penggunaan gadget akan membuat wawasan manusia semakin bertambah dan juga semakin luas serta pengaksesan informasi begitu mudah dan praktis.

Banyakanya manfaat yang didapat dari penggunaan gadget juga menurut Ishomuddin (2016: 348) terdapat dampak negatif penggunaan gadget bagi remaja di antaranya; dunia pendidikan gadget banyak disalah gunakan oleh kalangan remaja yang menempuh jenjang pendidikan tingkat SMP, SMA dan jenjang perkuliahan. Dalam proses pembelajaran pelajar/mahasiswan tidak lagi berusaha melakukan proses pembelajaran yang merujuk kepada teksbook tetapi lebih memilih kepada potong kompas atau copy paste dari sumber internet (media sosial) tanpa dicermati secara seksama.

Gadget dapat merusak akhlak ataupun moral remaja. Remaja dapat mengakses berbagai macam situs yang tidak pantas untuk dibuka atau ditonton seusia mereka, yang mengakibatkan remaja mengaplikasikannya dalam kehidupan sehari-hari terkait hal yang diakses di dalam gadget, seperti kekerasan, pornografi dan seks bebas.

Gadget juga dapat mengganggu kesehatan karena penggunaan gadget yang berlebihan, mengakibatkan kesehatan terganggu dan menyebabkan berbagai macam penyakit seperti insomnia dan mata sindrom.

Hubungannya dengan akhlak di awali dengan kita mengetahui pengertian akhlak terlebih dahulu. Akhlak berasal dari bahasa arab yaitu khuluqun yang artinya perangai atau kebiasaan. Menurut istilah akhlak adalah baik dan buruknya kebiasaan seseorang yang mengatur pergaulannya dan menentukan tujuan serta arah kebiasaannya (Habibah, 2015: 73). Imam Al-Ghazali juga berpendapat bahwa akhlak adalah perilaku yang melekat dalam jiwa manusia melahirkan perbuatan-perbuatan tanpa melalui proses pemikiran daan pertimbangan.

Ruang lingkup akhlak menurut Hasbi dan Teguh (2019: 78- 88) yaitu akhlak kepada Allah SWT. Perilaku dan ucapan yang baik terhadap Allah SWT melalui beribadah secara langsung kepada Allah seperti sholat, puasa, membayar zakat, naik haji dan berperilaku yang mencerminkan hubungan baik dengan Allah. Akhlak terhadap Rasulullah SAW juga ruang lingkup di dalamnya. Rasulullah adalah suri tauladan manusia yang paling baik akhlaknya, Rasululloh Saw mempunyai sifat yang dermawan, sabardan selalu menghindari perbuatan dosa. Maka dari itu manusia sebagai ummat Rasululloh Saw wajib meneladani akhlaknya dengan menjunjung tinggi akhlakul karimah sebagai rasa terimakasih atas perjuangannya membawa ummat manusia ke jalan yang di ridhoi Allah. Terakhir yaitu akhlak terhadap sesama manusia karena Islam 
mengajarkan agar manusia menjaga jasmani dan rohaninya. Jasmani manusia harus dipelihara dengan memberikan konsumsi makanan yang halal dan baik. Islam mengajarkan agar manusia menjaga kehormatan diri baik laki-laki maupun perempuan serta menjaga akhlak terhadap sesama manusia.

Penelitian ini berfokus pada subjeknya yaitu remaja dimana menurut Efendi (2009: 221) Masa remaja adalah masa pancaroba dari masa kanak-kanak ke masa dewasa. Batasan usia remaja adalah dari 12 sampai 24 tahun. Remaja berada diantara fase anak dan dewasa yang ditandai dengan adanya perubahan fisik, kognitif, biologis, emosi dan tingkah laku.

Menurut (Putro, 2017: 26) terdapat beberapa ciri-ciri dan perubahan yang terjadi selama masa peralihan dari anak-anak ke masa dewasa yaitu sebagai berikut; remaja mulai menuntut hak dan kebebasannya dalam hal menyampaikan pendapat, remaja lebih mudah terpengaruh oleh teman-temannya, perubahan fisik remaja yang luar biasa, dan emaja sulit menerima nasehat dari orang tuanya dikarenakan percaya diri yang tinggi.

Era globalisasi sekarang ini menjadi semakin maraknya remaja yang melanggar norma-norma agama dan sosial, mereka tidak mau mengikuti aturan-aturan yang telah di tetapkan di dalam masyarakat. Sumara dkk (2017: 347) juga berpendapat bahwa kenakalan remaja merupakan suatu tindakan yang menyimpang dari norma-norma hukum dan dapat merugikan dirinya sendiri serta orang lain. Contoh kenakalan remaja yaitu seks bebas, narkoba dan lain sebagainya.

\section{Metode Penelitian}

Jenis penelitian ini merupakan penelitian kuantitatif dengan menggunakan metode kolerasional. Populasi dalam penelitian ini berjumlah 42 orang, sedangkan sampel dalam penelitian ini peneliti mengambil keseluruhan populasi untuk dijadikan sampel yaitu berjumlah 42 orang. Teknik Pengumpulan data yang digunakan dalam penelitian ini yaitu melalui observasi dan angket. Untuk mendapatkan hasil dari peneltian ini penulis menyebarkan angket dengan 36 item pernyataan kepada remaja di Desa Simanuldang Jae yaitu sebanyak 42 orang. Kemudian untuk mengolah data penulis menggunakan Microsoft Excel dan SPSS 20 For Windows.

\section{Hasil dan Pembahasan}

Peneliti menggunakan uji hipotesis analisis data regresi linier sederhana untuk mendapatkan hasil penelitian, yang bertujuan untuk untuk memprediksi pengaruh antara variabel X (penggunaan gadget) dengan variabel Y (akhlak remaja).

\section{A. Hasil Uji T}

Pengujian hipotesis uji $\mathrm{t}(\mathrm{t}$-test) yang digunakan dalam penelitian ini yaitu bertujuan untuk mengetahui apakah pengaruh variabel $\mathrm{X}$ terhadap variabel $\mathrm{Y}$ signifikan atau tidak. Dengan rumus jika $t_{\text {hitung }}>t_{\text {tabel }}$ atau nilai signifikansinya kurang dari 0,05 maka dapat dikatakan hasil uji $\mathrm{T}$ atau hasil penelitiannya signifikan. 


\begin{tabular}{|c|c|c|c|c|c|}
\hline \multicolumn{6}{|c|}{ Coefficients } \\
\hline \multirow[t]{2}{*}{ Model } & \multicolumn{2}{|c|}{$\begin{array}{c}\text { Unstandardized } \\
\text { Coefficients }\end{array}$} & \multirow{2}{*}{$\begin{array}{c}\text { Standardized } \\
\text { Coefficients }\end{array}$} & \multirow[t]{2}{*}{$\mathbf{t}$} & \multirow[t]{2}{*}{ Sig. } \\
\hline & B & Std. Eror & & & \\
\hline (Constant) & 49.719 & 7.488 & .435 & 6.639 & .000 \\
\hline Penggunaan Gadget & .467 & .153 & & 3.059 & .004 \\
\hline
\end{tabular}

Berdasarkan hasil uji $\mathrm{T}$ diatas dengan rumus $\mathrm{N}=42-2$ maka diperoleh $\mathrm{t}_{\text {tabel }}$ nya yaitu 1.681 dan $\mathrm{t}_{\text {hitung }} 3.059$ dan nilai signifikansinya sebesar $0.04<0.05$ maka dapat disimpulkan hasil uji T penelitian ini signifikan dengan Ha diterima dan Ho ditolak. Sehingga dapat disimpulkan bahwa terdapat pengaruh yang signifikan antara penggunaan gadget $(\mathrm{X})$ terhadap akhlak remaja (Y) di Desa Simanuldang Jae Kecamatan Ulu Barumun Kabupaten Padang Lawas.

\section{B. Hasil Koefisien Determinasi}

Tabel 4.2

Model Summary

\begin{tabular}{ccccc}
\hline Model & $\mathbf{R}$ & $\boldsymbol{R}$ Square & Adjusted $\mathbf{R}$ Square & $\begin{array}{c}\text { Std. Eror of the } \\
\text { Estimate }\end{array}$ \\
\hline $\mathbf{1}$ & $.435^{\mathrm{a}}$ & .190 & .169 & 7.125 \\
\hline
\end{tabular}

Koefesien determinasi $\left(\mathrm{R}^{2}\right)$ bertujuan untuk mengetahui seberapa besar variabel X (Penggunaan Gadget) mempengaruhi variabel Y (Akhlak Remaja) di Desa Simanuldang Jae. Berdasarkan tabel di atas maka dapat disimpulkan bahwa koefesien kolerasi $\left(\mathrm{R}^{2}\right)$ nya sebesar $0,190(19,0 \%)$ Hal ini menunjukkan bahwa variabel X (penggunaan gadget) mempengaruhi variabel Y (akhlak remaja) sebanyak 19\%. sedangkan sisanya yaitu $81 \%$ lagi dipengaruhi oleh variabel lain yang diluar penelitian.

Pengaruh positif gadget terhadap akhlak remaja di Desa Simanuldang Jae dilihat dari hasil presentse kuisioner yaitu sebanyak $21.42 \%$ mengatakan remaja mengakses berita yang berbasis Islami, yang artinya adanya remaja yang mengakses berita berbasis Islami sehingga berpengaruh baik terhadap akhlaknya. Contohnya, remaja yang terkadang masih membentak orangtuanya sekarang sudah berkata lemah lembut terhadap orangtuanya dikarenakan mengakses berita yang berbasis Islami atau video ceramah tentang berbakti kepada kedua orangtua.

Pengaruh negatif penggunaan gadget terhadap akhlak remaja di Desa Simanuldang Jae dilihat dari jawaban kuisioner responden yaitu sebanyak $73.80 \%$ yang menyatakan terkadang mereka tidak patuh terhadap perintah orangtuanya ketika sedang menggunakan gadget. Artinya, sebagian besar remaja di Desa Simanuldang Jae tidak patuh terhadap perintah orangtua mereka ketika sedang menggunakan gadget dan sering menunda pekerjaan yang disuruh oleh orangtuanya. Selain itu mereka juga lalai dalam melaksanakan sholat wajib dikarenakan penggunaan gadget, terlihat dari hasil jawaban kuisioner responden yang menyatakan mereka kurang setuju dengan pernyataan saya selalu melaksanakan 
sholat wajub sebangak $42.85 \%$. Remaja juga terkadang kurang fokus terhadap kawannya yang berbicara ataupun bercerita dikarenakan sibuk dalam menggunakan gadget. Terlihat dari hasil jawaban kuisioner responden yang menyatakan mereka tidak setuju dengan pernyataan saya berhenti bermain gadget ketika teman saya mengajak ngobrol sebanyak $45.23 \%$.

\section{Simpulan}

Penelitian ini dilakukan untuk mengetahui seberapa besar pengaruh penggunaan gadget terhadap akhlak remaja serta bagaimana pengaruh positif dan negatif penggunaan gadget terhadap akhlak remaja di Desa Simanuldang Jae Kecamatan Ulu Barumun Kabupaten Padang Lawas. Berdasarkan hasil penelitian dapat disimpulkan bahwa terdapat pengaruh yang signifikan antara penggunaan gadget terhadap akhlak remaja di Desa Simanuldang Jae Kecamatan Ulu Barumun Kabupaten Padang Lawas. Baik itu pengaruh positif atau pengaruh negatif.

\section{Referensi}

Andalia, F. \& Setiawan, E. B. (2015). Pengembangan Sistem Informasi Pengolahan Data Pencari Kerja Pada Dinas Sosial Tenaga Kerja Kota Padang. Jurnal Ilmiah Komputer dan Informatika. 4 (2): 93.

Efendi, F. \& Makhfudli. (2009). Keperawatan Kesehatan Komunitas. Jakarta: Salemba Medika.

Habibah, S. (2015). Akhlak dan Etika dalam Islam. Jurnal Pesona Dasar. 1 (4): 73.

Hasbi \& Teguh, H. P. (2019). Pendidikan Agama Islam Era Modern. Yogyakarta: PT Leutika Nouvalitera.

Ishomuddin. (2016). Pembangunan Sosial Dalam Menghadapi Masyarakat Ekonomi Asean. Jawa Timur: Duta Media Publishing.

Iqbal, M. (2018). Psikologi Pernikahan. Depok: Gema Insani.

Novrian, A. (2017). Hubungan Antara Fungsi Keluarga dengan Kecenderungan Perilaku Bullying Pada Remaja Muslim Kelas IX SMP Negeri 3 Palembang. Skripsi. Palembang : Universitas Islam Negeri Raden Fatah.

Nofrion. (2016). Komunikasi Pendidikan. Jakarta.: Kencana.

Putro, K.H. (2017). Memahami Ciri dan Tugas Perkembangan Masa Remaja. Jurnal Aplikasi Ilтu-ilmu Agama. 17(1): 26.

Rochmah, E. Y. (2017). Psikologi Remaja Muslim. Jurnal Studi Kependidikan dan Keislaman. 3 (2): 193.

Rosyadi, I. (2019). Sobat Milenial. Depok: Guepedia.

Siyoto, S. \& Sodik, M. A. (2015). Dasar Metodologi Penelitian. Yogyakarta: Literasi Media Publishing. 
Sumara, D. Dkk. (2017). Kenakalan Remaja dan Penanganannya. Jurnal Penelitian PPM. 4 (2): 347.

Syahyuddin, D. (2019). Pengaruh Gadget Terhadap Pola Interaksi Sosial dan Komunikasi Siswa. Jurnal Kehumasan.2 (1): 276-277.

Yusuf, M. \& Daris, L. (2018). Analisis Data Penelitian Teori \& Aplikasi dalam Bidang Perikanan. Bogor: PT Penerbiy IPS Press. 